\title{
0 ANTIGO E $O$ MODERNO NA OBRA DE CLÁUDIO MANUEL DA COSTA
}

\author{
Laura de Mello e Souza
}

Universidade de São Paulo

\begin{abstract}
Resumo
Em mais de um aspecto, Cláudio Manuel da Costa foi um homem dividido e uma personalidade contraditória. Suas raízes regionais eram profundas e se evidenciam em toda a sua obra. Mas tinha estudado em Coimbra e não se cansava de opor o Ribeirão do Carmo ao Mondego. Era conservador e parece ter integrado o grupo de homens que pensaram em romper as ligações políticas entre Minas e Portugal. Delatou amigos e apareceu morto: muito presumivelmente, suicídio, outro indício da alma atormentada. O que se pretende indicar nesta comunicação é a marca da tradição clássica na obra de Cláudio, um dos poetas mais perfeccionistas e eruditos de seu tempo. Tal presença tem sido reconhecida por boa parte da crítica literária, e os escritos de Sérgio Buarque de Holanda sobre o assunto, publicados postumamente, constituem hoje argumento de autoridade. Este texto procura recuperar tanto os argumentos que comprovaram a presença dos autores clássicos em Cláudio quanto o modo original que o poeta encontrou para compor sua obra a partir dessa tradição, aproximando-se, talvez, daquela que foi a principal ruptura intelectual do século XVII no Ocidente: a polêmica entre antigos e modernos.
\end{abstract}




\section{0 letrado e sua produção}

Cláudio Manuel da Costa começou a escrever poemas ainda bem moço, publicando-os pela primeira vez quando estudava Cânones em Coimbra. Ali saíram, em opúsculos, o Culto métrico a uma abadessa do Mosteiro de Figueiró (1749); o Munúsculo métrico consagrado a d. Francisco da Anunciação, reitor da Universidade de Coimbra (1751); o Epicédio à morte de frei Gaspar da Encarnação, o Labirinto de amor e os Números harmônicos, (todos os três de 1753). De volta a Minas Gerais, ao que tudo indica no início de 1754, desempenhou funções junto às câmaras de Mariana e de Vila Rica, onde se estabeleceu como advogado, dos mais famosos, senão o mais de todos, dentre os que atuavam no lugar. Em 1768, publicaram-se, mais uma vez em Coimbra, as suas Obras: seleção feita pelo poeta, contemplando tudo quanto considerava bom de fato e deixando de lado os versos da primeira mocidade.

Nada mais foi dado ao público durante sua vida, apesar de ter continuado a escrever poesia e prosa. Em 1768, várias peças literárias em verso - um pequeno "drama", sonetos, uma écloga, uma ode - compuseram uma academia de circunstância em homenagem a José Luís de Meneses Abranches Castelo Branco e Noronha, conde de Valadares e governador de Minas. Entre 1769 e 1772, dedicou-se a um poema épico, o Vila Rica, inédito até 1839; nos anos seguintes - antes, com certeza, de 1775 - escreveu um Fundamento histórico que explicava e contextualizava a matéria do épico. Entre 1775 e 1780, elaborou várias Poesias em louvor de governantes ou de acontecimentos da época. Entre 1786 e 1788, presume-se que participou da realização das Cartas chilenas, hoje quase unanimemente atribuídas a Tomás Antonio Gonzaga, apesar de se reconhecer, também quase sem exceção, a autoria da "Epístola a Critilo” como sendo de Cláudio. Esta foi, com toda a probabilidade, sua última realização literária. ${ }^{1}$ Poucos o sabem, mas Cláudio foi ainda autor de uma Carta topográfica de Vila Rica e seu Termo, pela qual recebeu, em 1758, o pagamento de sessenta e quatro oitavas de ouro. ${ }^{2}$

Poeta, historiador e cartógrafo, Cláudio Manuel da Costa foi ainda dramaturgo, tradutor e, por fim, talvez compositor musical: além do Parnaso obsequioso,

\footnotetext{
${ }^{1}$ RIBEIRO, João. Cláudio Manuel da Costa. In: PROENÇA FILHO, Domício (org.). A poesia dos inconfidentes. Rio de Janeiro: Nova Aguilar, 1996, p. 5-26; AGUIAR, Melânia Silva de. A trajetória poética de Cláudio Manuel da Costa. In: PROENÇA FILHO, Domício (org.). A poesia..., p. 27-39. ${ }^{2}$ APM, Casa dos Contos, cx. 37, doc. 30.082.
} 
pode ter musicado uma ópera de Metastasio, Demofoonte em Trácia. ${ }^{3}$ Parte dessa obra vasta e variada se perdeu: a carta topográfica, por exemplo, nunca foi encontrada nos arquivos brasileiros e portugueses, bem como o Labirinto de amor e os Números harmônicos da mocidade ou a tradução da Riqueza das nações de Adam Smith, a qual, na verdade, sequer se tem certeza que haja um dia empreendido.

Cláudio Manuel atuou por várias vezes no Senado de Vila Rica - como terceiro vereador, juiz ordinário, juiz mais moço e, no fim da vida, juiz mais velho - e, segundo documentos, serviu como almotacé no ano de 1754 junto à Câmara de Mariana. ${ }^{4}$ Formal e informalmente, secretariou mais de um governador de Minas entre 1762 e 1783, alternando as funções administrativas e burocráticas com o exercício da advocacia. Foi, portanto, um letrado típico, suporte da governança, homem de leis e homem de letras.

Cláudio Manuel da Costa viveu na época áurea da Ilustração europeia. Nasceu em 5 de junho de 1729, no sítio da Vargem do Itacolomi, nas cercanias da Vila de Nossa Senhora do Ribeirão do Carmo, a mais antiga das Minas, elevada à categoria de cidade em 1745 com o nome de Mariana. Suicidou-se em 4 de julho de 1789, em Vila Rica, hoje Ouro Preto, um mês após completar os sessenta anos. A publicação das Obras em 1768 tornou-o conhecido em todo o mundo português e os que tinham acesso a seus trabalhos manuscritos, que circulavam entre os amigos e conhecidos, reconheciam-no como grande mestre do verso. No início do século XIX, autores ingleses e alemães referiram-se a ele como vulto destacado nas letras lusitanas, louvando-lhe as altas qualidades de sonetista.

Nos apontamentos biográficos que enviou para a Academia Brasílica dos Renascidos da Bahia, em novembro de 1759, Cláudio Manuel registra que foi “aplicado desde os primeiros anos ao estudo das Belas Letras”, conservando "em manuscritos rimas nas línguas latina, italiana, portuguesa, castelhana e francesa”, além da "poesia heróica e lírica” que, na época, já tinha publicado em "dois tomos in quarto". ${ }^{5}$ Como sua primeira obra impressa data de 1749 , ano em que chegou a Coimbra para seguir os cursos da Universidade, deve ter composto versos desde os tempos do colégio jesuítico do Rio de Janeiro, onde

\footnotetext{
${ }^{3}$ ESTEVES, Suely Maria Perucci. A Opera Demofoonte em Trácia: tradução e adaptação de Demofoonte, de Metastásio, atribuídas a Cláudio Manuel da Costa, Glauceste Satúrnio. Dissertação de Mestrado, FFLCH - USP, 2007.

${ }^{4}$ Idem, ib., p. 28.

${ }^{5}$ Documentos. In: LAMEGO, Alberto. Autobiografia e inéditos - Cláudio Manuel da Costa. In: Revista da Academia Brasileira de Letras, janeiro de 1912, vol. IV, p. 5-25.
} 
esteve entre 1746 e 1749, ou quem sabe desde a meninice na Vila do Carmo, quando não contava sequer com catorze anos. A se acreditar no seu próprio testemunho, Cláudio foi, portanto, poeta durante cerca de meio século.

\section{Antigo, moderno e dividido}

Apesar disso, muito tempo se passou até que Cláudio Manuel da Costa gozasse de popularidade próxima à alcançada por outros contemporâneos seus. No que diz respeito ao poema épico Vila Rica, não sustenta comparação tanto com o belo Uraguay de Basílio da Gama - publicado em 1769 - quanto com o Caramuru de frei José de Santa Rita Durão, menos elegante, mais pesado e impresso em Lisboa em 1781. A lírica de Cláudio também ficou em segundo plano quando confrontada com os poemas leves, simples e melodiosos de Tomás Antonio Gonzaga, publicados pela primeira vez em 1800, quando seu autor vivia degredado em Moçambique por crime de inconfidência, e transformados, em cerca de uma década, num verdadeiro best-seller. Para se ter uma ideia da desproporção, entre 1768 e 1903, a lírica de Cláudio conheceu apenas duas edições, ao passo que, até 1930, a de Gonzaga havia alcançado o marco de quarenta e sete edições em língua portuguesa e nove em outras línguas. ${ }^{6}$ Gonzaga era, além de tudo, considerado mais moderno pela crítica: árcade e ilustrado, sem sombra de dúvida, qualidades menos evidentes em Cláudio, que se aproximava das ideias e da estética setecentistas em alguns poemas, mas, em outros, mantinha o tom gongórico do século XVII. Num estudo monumental e definitivo, Sérgio Buarque de Holanda considerou-o predominantemente barroco, mostrando também como, para corrigir o passadismo mais pesado, recorria com frequência à lírica do Renascimento. Na Formação da literatura brasileira, Antonio Candido destacou os traços liminares do poeta: Cláudio teria permanecido no limiar do estilo novo, anunciando-o, mas não chegando a praticá-lo, ou se arriscando nele com certa hesitação. ${ }^{7}$

João Ribeiro, em muitos sentidos o principal precursor da crítica mais especializada e erudita que analisou a obra de Cláudio ao longo do século XX,

\footnotetext{
${ }^{6}$ Cronologia da vida e obra de Cláudio Manuel da Costa e Cronologia da vida e obra de Tomás Antonio Gonzaga. In: PROENÇA FILHO, Domício, op. cit., p. LVIII-LXII.

${ }^{7}$ BUARQUE DE HOLANDA, Sérgio. Capítulos de literatura colonial. Organizaçãoe introdução deAntonio Candido. São Paulo: Brasiliense, 1991; CANDIDO, Antonio. Formação da literatura brasileira Momentos decisivos -1750-1880. 10ª edição revista pelo autor. Rio de Janeiro: Ouro sobre Azul, 2006.
} 
ponderou que os “mestres” e "modelos" do poeta foram os mesmos de todo árcade: Virgílio, Ovídio, Teócrito, na Antiguidade; Petrarca, no Renascimento; Quevedo, no Seiscentos; Metastasio, no seu tempo. ${ }^{8}$ A mistura do antigo com o moderno foi, portanto, elemento distintivo da Arcádia, e a liminaridade de Cláudio teria sido a da própria escola que abraçou. Gonzaga foi além, bem mais moderno que antigo, dotado, continua João Ribeiro, de luz própria, repugnandonos, por isso, classificá-lo entre os árcades: "damos-lhe logo um lugar entre os precursores do romantismo". ${ }^{9}$

Os julgamentos sobre o autor e a obra começaram a mudar bastante, contudo, desde a publicação póstuma dos ensaios de Sérgio Buarque de Holanda sobre a Arcádia e, mais especificamente, sobre a poesia de Cláudio Manuel da Costa. Esses ensaios destacaram a sofisticação formal e a ambiguidade dos poemas, espelho, aliás, dos conflitos inconciliáveis do seu autor. Cláudio, tudo indica, gostaria de ser moderno, de acertar o compasso com o seu tempo. Atingiu parcialmente o intento nas composições polidas na segunda fase da vida, ao longo da década de 1760, culminando com a publicação das Obras e a apresentação do Parnaso obsequioso na forma de academia circunstancial, ambas em $1768 .{ }^{10} \mathrm{O}$ peso da tradição, dos anos formativos em Coimbra, antes que “a lição dos Gregos, Franceses e Italianos” se impusesse e que o gosto das belas letras começasse a melhorar em Portugal - como ele mesmo escreveu no prólogo das Obras -, tudo isso o acabou empurrando para trás, em direção ao seiscentismo: em 1756, quando se fundou no Reino a Arcádia Lusitana, Cláudio já se achava de volta às Minas. Por isso, contrafeito, tomou emprestada de Ovídio a passagem frequentemente citada pela crítica e que define bem suas tendências estéticas ambivalentes: "É infelicidade que haja de confessar que vejo e aprovo o melhor, mas sigo o contrário na execução". ${ }^{11}$

Nos primeiros poemas, que remontam ao final da década de 1740 e ao início de 1750, a língua é barroca, pesada, a pontuação é abstrusa - como observou Melânia Silva de Aguiar -, tudo resultando numa leitura difícil e pouco atraente. Já os Sonetos, que começou a compor em Coimbra, mas limou durante quase

\footnotetext{
${ }^{8}$ RIBEIRO, João, op. cit., p. 13.

${ }^{9}$ Idem, ib., p. 13.

${ }^{10}$ AGUIAR, Melânia Silva de. A trajetória poética... In: PROENÇA FILHO, Domício. (org.), op. cit., p. 31.

${ }^{11}$ COSTA, Cláudio Manuel da. Prólogo ao leitor. Obras. In: A poesia dos inconfidentes, op. cit., p. 48
} 
vinte anos - foi um revisor obsessivo da própria obra - são belos e mais claros, mas debaixo da linguagem mais natural há, conforme demonstrou Sérgio Buarque de Holanda, camadas de significados e de tradições culturais diversas, revelando uma erudição igualada poucas vezes nas letras luso-americanas. Cláudio se mostra assim como um poeta denso, de grande complexidade retórica, a exigir do leitor - sempre seguindo Melânia Aguiar - atenção muito maior do que a demandada pela maioria dos poetas árcades. ${ }^{12}$

Tanto na fase da mocidade, quanto na das Obras e, ainda, na terceira, quando compôs muitos dos poemas encomiásticos, o épico Vila Rica, a Epístola a Critilo, e colaborou nas Cartas chilenas, Cláudio manteve um olho no verso mais livre do seu tempo e o outro nos ensinamentos dos antigos e do seiscentismo. Além do repertório comum aos árcades - os já referidos Virgílio, Ovídio e Teócrito -, o poeta se inspirou na Farsália, de Lucano, sobretudo no apego às fábulas, expresso na Fábula do Ribeirão do Carmo e no Vila Rica. O recurso às fábulas, naquele momento, teria servido, segundo Sérgio Buarque de Holanda, para "suprir a mudez do lírico". ${ }^{13}$ Ou seja: os versos juvenis davam voz ao "desencanto e à nostalgia do degredado"; os maduros, desejosos de "honrar o pátrio berço”, liquidavam “os aspectos mais sórdidos da realidade circunstante” para substituí-los por “imagens forjadas segundo os padrões ilustres” que haviam saturado sua fantasia, educada no convívio permanente com os clássicos latinos. E Buarque de Holanda conclui: "Em outras palavras, tirar do nada uma espécie de mitologia, por onde o seu mundo natal viesse a ganhar dignidade e decoro" ${ }^{14}$

Discrepando de outros contemporâneos, alguns bem mais moços que ele, como Gonzaga, Cláudio temeu a espontaneidade e seguiu a lição dos que, antigos mas também modernos, ressaltaram as virtudes do polimento dos versos, a lima, como costumava dizer o poeta de Mariana. Os poemas deveriam repousar por anos até serem dados ao público: como pontificou Gianbattista Marino, "nenhuma página passou jamais à imortalidade antes de ser invadida pela poeira e nenhum livro pôs o freio nos dentes da inveja sem ter sido mordido primeiramente pela traça”. Na Antiguidade, o procedimento de polir os versos e deixá-los descansar antes que pudessem enfrentar a eternidade foi defendido na Arte poética de Horácio. No Setecentos, conforme Sérgio Buarque de Holanda,

\footnotetext{
${ }^{12}$ AGUIAR, Melânia Silva de. A trajetória poética..., op. cit., p. 29.

${ }^{13}$ BUARQUE DE HOLANDA, Sérgio. A arcádia heróica. In: Capítulos de literatura colonial , op. cit., p. 158.

${ }^{14}$ Idem, ib., p. 158.
} 
esta obra se tornou uma verdadeira bíblia dos poetas. É este, aliás, o significado do emblema da tartaruga posta sob a estátua de Minerva. ${ }^{15}$ Antes do século XIX, é sempre bom lembrar, a linguagem da emoção deveria se sujeitar a um controle rigoroso das regras racionais: visando a forma perfeita, a lima, como escreveria Vittorio Alfieri no final do Setecentos, era o antônimo da febre criadora. ${ }^{16}$

Dos modernos, Cláudio bebeu e parodiou a obra de expoentes do seiscentismo como Góngora e Lope de Vega, mas também a de ícones do Renascimento, como Petrarca, Torquato Tasso, Sá de Miranda, Diogo Bernardes e, claro, Luís de Camões. No fim da vida, emulou Voltaire: a Henríada é a grande inspiração do poema Vila Rica que, sem grande sucesso, lança mão do modelo francês dos versos emparelhados. Numa dissertação recente, Djalma Expedito de Lima destacou o fato de algumas das notas do poema épico - notas em poema seguem também o modelo de Voltaire - mostrarem certa faceta até agora inexplorada do poeta, comprovando mais uma vez como era variada a sua erudição. Para melhor fundamentar as considerações sobre a vida e costumes dos indígenas do sertão mineiro, Cláudio invocou três obras hispânicas que versavam sobre assuntos análogos nas regiões americanas vizinhas: a Historia mexicana de Antonio de Solis e Rivadeneira -, que fazia parte da biblioteca depois confiscada a Cláudio, quando de sua prisão; a epopeia Araucana, de d. Alonso de Ercilla, e a Monarquia indiana, de Juan de Torquemada. ${ }^{17}$

Djalma Expedito vê na referência a Solis o reconhecimento à autoridade de Voltaire que, no Essai sur la poésie épique, o reputa “excelente”. O percurso seria, assim, curioso, bem típico dos dilemas próprios ao letrado colonial da época: por intermédio da Ilustração europeia, o luso-americano se dava conta das relações horizontais que uniam as manifestações culturais hispano-americanas. Mas será que a vizinha América Hispânica só poderia ser mesmo observada por meio dos olhos da França ilustrada?

Atormentado e melancólico, conforme evidenciado no belo estudo de Sérgio Alcides, Cláudio Manuel da Costa foi o mais complexo dos poetas de seu tempo.

\footnotetext{
${ }^{15}$ BUARQUE DE HOLANDA, Sérgio. Cláudio Manuel da Costa. In: Capítulos de literatura colonial, op. cit., p. 256.

${ }^{16}$ Idem, ibidem, p. 351. ALFIERI, Vittorio. Vita. A cura di Anna Dolfi. Milão: Mondadori, 1987, p. 289 [Oscar Classici Mondadori]. Cf. ALCIDES, Sérgio. Estes penhascos - Cláudio Manuel da Costa e a paisagem de Minas - 1753-1773. São Paulo: Hucitec, p. 73 e segs.

${ }^{17}$ LIMA, Djalma Espedito de. Aépica de Cláudio Manuel da Costa - uma leitura do poema Vila Rica. Dissertação de Mestrado, Departamento de Letras Clássicas e Vernáculas, FFLCH - USP, 2007, p. 70.
} 
Tentou escapar das imagens convulsionadas da estética barroca, buscando aquelas que, mais serenas, contrastassem melhor com o tumulto que lhe ia n'alma. Por baixo do pensamento agudo e das frases ordenadas, não pôde, entretanto, esconder as emoções profundas, o desengano e o desespero permanentes, para Sérgio Buarque de Holanda bem lusitanos, aliás. ${ }^{18}$

Gonzaga, filho de magistrado luso-brasileiro, mas nascido no Reino, poderia se dar à novidade do estilo simples e despojado. Cláudio, filho de português obscuro e arrivista, neto de oficial mecânico, nascido às margens de um regato aurífero sujo e poluído - o “turvo ribeirão” vezes sem conta invocado nos poemas - agasalhava-se na estética mais canônica do Barroco da mesma forma que os bacharéis brasileiros do Império se esconderiam detrás dos circunlóquios e do rebuscamento formal para compensar um inelutável sentimento de inferioridade.

\section{Natureza e cultura}

As Obras, conforme lembrou João Ribeiro, foram “o primeiro livro de poeta nacional” (leia-se luso-brasileiro) “que chegava ao Brasil” (leia-se América portuguesa), um ano antes do celebrado Uraguay de Basílio da Gama. Logo abaixo da especificação da autoria e da dedicatória, Cláudio escolheu uma citação tirada das Geórgicas, de Virgílio:

Primus ego in Patria mecum, modo vita supersit

Aonio rediens deducam vertice Musas.

Ou seja:

No pouco de vida que me resta, eu, o primeiro que volta,

Levarei comigo do monte aônio as Musas para a Pátria.

Na ausência de um texto autobiográfico mais extenso e detalhado, como a "Breve notícia da perseguição movida contra a Venerável Companhia de Jesus em Portugal”, em que frei José de Santa Rita Durão deu conta dos principais acontecimentos de sua vida, ${ }^{19}$ é necessário ler a obra poética de Cláudio Manuel

\footnotetext{
${ }^{18}$ BUARQUE DE HOLANDA. Sérgio, op. cit., p. 331-357. AMARAL, Sérgio Alcides Pereira do. Estes penhascos...., op. cit.

${ }^{19}$ Breve notícia da perseguição movida contra a Venerável Companhia de Jesus em Portugal; e da nefanda conspiração tramada por alguns fidalgos contra a vida do rei fidelíssimo, escrita por Frei José de Santa Rita Durão, religioso agostinho e doutor na sagrada teologia. In: VIEGAS, Arthur. O poeta Santa Rita Durão - revelações históricas de sua vida e do seu século. Bruxelas/
} 
da Costa a contrapelo, buscando indícios esclarecedores. Os poucos escritos deixados pelo poeta à guisa de “dedicatórias”, “prólogos” ou fechos de seus versos, como o escrito "Para terminar a Academia", do Parnaso obsequioso, são, assim, muito importantes. Em que pesem os aspectos retóricos e tópicos, fundamentais na época e hoje muito valorizados pela crítica, o prólogo às Obras registra o dilaceramento do homem de letras que, pertencendo a um universo de cultura europeu, tributário de um legado que remonta à Antiguidade, vê-se compelido a extrair matéria poética do ambiente circundante, com o qual, aliás, sente-se cada vez mais identificado, aspirando, "desde os sertões da capitania das Minas Gerais”, a brindar o leitor “com o pequeno obséquio destas Obras”:

Não permitiu o Céu que alguns influxos, que devi às águas do Mondego, se prosperassem por muito tempo: e destinado a buscar a Pátria, que por espaço de cinco anos havia deixado, aqui entre a grossaria dos seus gênios, que menos pudera eu fazer que entregarme ao ócio, e sepultar-me na ignorância! Que menos, que abandonar as fingidas Ninfas destes rios e no centro deles adorar a preciosidade daqueles metais, que têm atraído a este clima os corações de toda a Europa! Não são estas as venturosas praias da Arcádia, onde o som das águas inspirava a harmonia dos versos. Turva, e feia, a corrente destes ribeiros, primeiro que arrebate as ideias de um Poeta, deixa ponderar a ambiciosa fadiga de minerar a terra, que lhes tem pervertido as cores. ${ }^{20}$

Na dedicatória a Sebastião José de Carvalho e Melo, que acompanha a “Écloga III”, Cláudio desabafaria:

Saio dos montes; vivo na incultura; comunico a rusticidade: não é muito que tudo o que concebo seja dissonância, e seja barbarismo tudo o que pronuncio. ${ }^{21}$

Ao celebrar o aniversário do conde de Valadares, governador das Minas, a quem dedicou o Parnaso obsequioso, Cláudio lamentaria a desproporção entre o anseio de cultuar as musas e a limitação do meio. Sem as musas não havia história, pois a memória dos feitos se perdia; para poetas do sertão, não restava alternativa senão ir tangendo acanhadamente a lira possível. Cláudio

Paris: L’Edition d’Art Gáudio, 1914, p. 5-69.

${ }^{20}$ Prólogo..., op. cit., p. 47.

${ }^{21}$ Écloga III - Albano - Louva-se a pacificação da guerra, mediante a direção do ilustríssimo e excelentíssimo senhor Sebastião José de Carvalho e Melo, Conde de Oeiras, Primeiro Ministro de Portugal etc. - Oferecida ao mesmo Senhor Juxta illud Ovid. Trist./Si poteris vácuo tradi. In: PROENÇA FILHO, Domício. A poesia dos inconfidentes..., op. cit., p. 142-143. 
suplicava ao conde que relevasse "a desconcertada harmonia" das musas locais que contemplavam Valadares e, mesmo reconhecendo-se inábeis, desejavam elogiá-lo. Como naquele ato de celebração ocorria, simultaneamente, a fundação de uma Arcádia ultramarina, o governador ficava sendo escolhido o seu custode. Esperava-se que, com o tempo, homens como ele e iniciativas como aquela acabassem polindo e civilizando o meio inculto:

Uns gênios educados em um tão bárbaro país, em um país acostumado mais a ouvir os rugidos das feras que a harmonia das Musas, como poderiam produzir cadências que fossem dignas de chegar a uns ouvidos que se criaram entre a delicadeza, ao concerto? Era temeridade esperá-lo: mas oh! Que este mesmo desalinho, este mesmo desmancho é em que mais nos afiançamos para devermos conceber a ideia de ver algum dia em melhor sorte trocada a rudeza que nos é tão natural.

Bom governo e proteção às musas acarretariam o triunfo da cultura sobre a natureza: "ela nos produziu, nos criou e nos conservou entre ásperos e intratáveis rochedos, no meio da barbaridade, no seio da rudeza, do desalinho e da incultura. Se agora por V. Exa. se veem amparadas as musas, converter-se-ão com maravilhosa metamorfose a barbaridade em polícia, a incultura em asseio, e o desalinho em gala”, concluiria Cláudio.

Como observado por mais de um autor, as poesias encomiásticas e o louvor aos homens de governo foram muito mais do que mera bajulação. Nelas, bem como em outros poemas de Cláudio, há ecos de reflexões centrais do século XVIII: os limites entre o governo forte e o governo justo, as relações entre a natureza e a cultura, a cidade - espaço preferencial das Luzes - e o campo onde, para homens como Rousseau, a virtude encontrava ambiente acolhedor. Apesar da linguagem muitas vezes pesada e afeita à tradição, Cláudio, letrado colonial, foi aos poucos se rendendo às Luzes, flertando com o despotismo ilustrado, reverenciando Carvalho e Melo. Traduziu uma Ode de Voltaire em homenagem a Frederico II da Prússia, invocou Pedro o Grande nos versos do Vila Rica, exaltando, desta maneira, o triunfo do governo duro sobre as forças descontroladas às quais, na falta dele, ficava entregue a sociedade.

O encômio educou Cláudio para a Ilustração, e o poema épico Vila Rica, que não conseguiu limar e chegou até nós em forma bruta e imperfeita, é o coroamento da sua reconciliação com a pátria mineira, local onde os ideais ilustrados poderiam se viabilizar desde que contassem com o esforço de homens aptos. No épico, Cláudio enalteceu os paulistas por terem interiorizado a presença portuguesa na América: 
Os ásperos sertões, que as mesmas feras

Talvez temeram povoar, já rompe

Sem susto algum o português vassalo...

Diante dessa ação normatizadora, os própriosíndios se mostraram reconhecidos:

Eu e os meus, que habitando as toscas grutas,

Vivendo só do acaso e da miséria,

Endurecendo a pele à calma, ao frio,

Sem mais abrigo que o estéril junco,

Vagos e errantes de um em outro serro,

Já conhecemos a civil polícia

Do teto e do vestido; unidos todos

Em doce paz, os frutos já provamos

Da concórdia, e do amor; ajuda um braço

O braço de outro; as sementeiras crescem,

E o trabalho comum é comum prêmio...

\section{Ah! Que de feras nos tornamos homens!}

Havia tempo que o poeta se ia rendendo ao impacto do meio, talvez porque adivinhasse residir ali a sua condição de originalidade - noção esta que começava a se firmar, conforme aquele mundo se tornava moderno. A repugnância original revelava-se antes retórica que sentimento genuíno:

Leia a posteridade, ó pátrio rio,

Em meus versos teu nome celebrado,

Porque vejas uma hora despertado

O sono vil do esquecimento frio:

Não vês nas tuas margens o sombrio,

Fresco assento de um álamo copado;

Não vês Ninfa cantar, pastar o gado,

Na tarde clara do calmoso estio.

Turvo, banhando as pálidas areias,

Nas porções do riquíssimo tesouro

O vasto campo da ambição recreias.

Que de seus raios o planeta louro,

Enriquecendo o influxo em tuas veias

Quanto em chamas fecunda, brota em ouro.

Num soneto recitado por ocasião da academia do Parnaso obsequioso, em 1768, Cláudio havia pedido às musas do seu ribeirão natal que o desculpassem por 
continuar invocando as do Tejo e do Mondego. ${ }^{22}$ Em 1773, no Vila Rica, parece mais apaziguado, percebendo que havia matéria poética para todas, mesmo se variada e inconciliável. Vencido o remorso, o poeta podia ir-se distanciando do Reino:

Não é valente, não, o que se inflama

No criminoso ardor de a cada instante

Dar provas de soberbo e de arrogante.

Os europeus são fáceis nesse arrojo.

Desdobrando a velha temática da oposição entre corte e aldeia, punha na boca do herói Antonio de Albuquerque a consideração de que a pátria não talhava o herói:

Nascem de aldeias

Almas insignes, de virtudes cheias,

E nem sempre na Corte nobre e clara

Ingênua série, portentosa e rara

Se vê de corações, que se engrandecem

Pela glória somente, e nela crescem.

Por fim, as curiosas notas do Vila Rica alusivas a poemas hispânicos reforçam um olhar ainda tímido, é verdade, filtrado talvez pelas Luzes da Europa, mas que, atento às especificidades - ao que era diferente e se insinuava nos interstícios do que era comum -, começava a ensaiar considerações aparentadas ao que hoje chamaríamos de relativismo cultural. Buscando exemplos "laterais”, Cláudio desconfiava que as Américas ibéricas tinham muito de comum entre si, sendo comparáveis, por exemplo, no heroísmo dos agentes da Coroa. Quando ressalta as virtudes heróicas de Antonio de Albuquerque - pacificar os emboabas, criar vilas, tomar as rédeas do governo, promulgar as leis do soberano - considera-o digno do elogio que Antonio de Solis e Rivadeneira fizera a Cortés na Historia mexicana: “Admirável conquista, e sempre ilustre capitão! Daqueles que vagarosamente produzem os séculos, e de que há raros exemplos na História”. ${ }^{23}$

As Américas mostravam-se comparáveis igualmente nos costumes de seus habitantes naturais. Argante, um dos protagonistas indígenas do poema, era

\footnotetext{
22 "Ninfas do pátrio Rio, eu tenho pejo//Que ingrato me acuseis vós outras, quando//Virdes que em meu auxílio ando invocando//As Ninfas do Mondego, ou as do Tejo”. In: A poesia dos inconfidentes, op. cit., p. 337.

${ }^{23}$ Fundamento histórico. In: A poesia dos inconfidentes, op. cit., p. 372.
} 
capaz de abrir uma cova funda, plantando no meio dela uma estaca aguda e a disfarçando por meio de uma cobertura feita com ramos, folhas moles e taipa de terra, a superfície apresentando-se, ao final, "limpa e pura". "Artifício", observou o poeta em nota, "de que usam os índios, tanto para colherem a caça, como nas ocasiões de guerra”, encontrado também entre os habitantes naturais do vicereino do Peru e registrado por d. Alonso de Ercilla na sua obra Araucana. ${ }^{24}$

A comparação podia ainda deslizar em direção aos traços humanos dos índios, revelando que eram mais nobres e mais próximos dos europeus do que se poderia ter cogitado de início. Ao referir-se a um índio Manaxó que, junto com os de seu povo, voluntariamente visitava Albuquerque, o poeta descreve o penacho branco que lhe adornava a cabeça, a plumagem amarela que lhe pendia, amarrada, dos braços, a tinta de urucu a lhe conferir ar de bravura: "a cor, nem preta,// nem branca por extremo...”, observando na nota que o índio podia ser aproximado do príncipe Guatimosin, sobrinho do imperador Montezuma, tal como fora retratado na obra de Solis: "El color tan inclinado a lo blanco, o tan lejos de la obscuridad,// que parecia estranjero entre los de su nación”.25

A humanidade dos índios se expressava também na arte que eram capazes de produzir, mesmo se diferente da dos europeus. Quando trata do contentamento reinante entre os Monaxós por causa do casamento de Garcia Rodrigues, paulista, e Lindoia, índia, Cláudio registra o som de apitos - "nem presumas// que se ignora da música o concerto// entre os crus Manaxós” - e comenta: “Nem presumas. Os índios da costa do Brasil, ainda que bárbaros, não desconhecem a música e a dança: estas singularidades foram mais bem notadas nos da nova Espanha, como nota Juan de Torquemada, Monarch. Indiana, Liv. 13, p. 26 e seguintes, tomo 2 e outros”. ${ }^{26}$

Na década de 1770, portanto, quando terminou o poema épico Vila Rica destinado a correr manuscrito e a permanecer inédito até 1839 - Cláudio Manuel da Costa era um homem bem diferente daquele regressado de Coimbra em 1753. A saudade do Tejo e do Mondego, que deve ter sido efetiva nos primeiros anos, havia se transformado em tópica ressequida. A emulação dos antigos se tornara mais rala, convivendo com a de um ou outro cronista da América espanhola e, sobretudo, com a do ilustrado francês Voltaire.

\footnotetext{
${ }^{24}$ Idem, p. 438 e p. 1.089.

${ }^{25}$ Vila Rica. In: A poesia dos inconfidentes..., op. cit., nota 35, p. 1.084.

${ }^{26}$ Vila Rica. In: Idem, p. 411 e p. 1.088.
} 
Na juventude, Cláudio foi cultor de Góngora e, com certeza, também de Boileau, paladino dos antigos na célebre querela que dividiu a vida intelectual francesa e europeia nos séculos XVII e XVIII. Formou-se entre os clássicos, hesitando ante a linguagem nova. Homem maduro, e depois, na década de 1780, na soleira da velhice, inclinou-se ante as novidades das Luzes, tanto no plano da criação quanto no das ideias, envolvendo-se no movimento da Inconfidência e sendo acusado de crime de lesa-majestade. Cláudio foi ambivalente como os homens de seu tempo, ao mesmo tempo abelha e aranha, para usar as metáforas de Marc Fumaroli.

Abelha, sugando o néctar de flores diferentes para fabricar seu próprio mel e sua própria cera: transformando e confundindo a matéria emprestada à tradição para transformá-la em obra própria, como escreveu Montaigne, cultor dos antigos. Aranha, extraindo de dentro de si "o fio abstrato com que fazia sua teia geométrica”, ou, para lançar mão de outra imagem, limando racional e obsessivamente seus versos. ${ }^{27}$

Os melhores dentre os versos de Cláudio Manuel da Costa que chegaram até nós não são, hoje, nem antigos, nem modernos. Como diria outro grande poeta nosso, este do século XX - Carlos Drummond de Andrade -, tornaram-se eternos.

\footnotetext{
${ }^{27}$ FUMAROLI, Marc. Les abeilles et les araignées - introdução a La querelle des anciens et des modernes - XVIIe - XVIIIe siècles . Paris: Gallimard, 2001, p. 11 e p. 216-218.
} 